\title{
A New Atherogenic Effect of Saturated Fatty Acids
}

\section{R. POLEDNE ${ }^{1}$}

${ }^{1}$ Center for Experimental Medicine, Institute for Clinical and Experimental Medicine, Prague, Czech Republic

Received August 2, 2012

Accepted August 31, 2012

On-line December 13, 2012

\section{Summary}

There is increasing evidence that dietary saturated fatty acids (SAFA) have not only an indirect atherogenic effect due to increasing LDL-cholesterol concentration but also a direct effect by activating the inflammation process. This review summarizes several recent publications in this field. The effect of SAFA on the inflammation process mediated by Toll-like receptor 4/NF-KB pathway has been well documented in various in vitro culture studies of macrophages and adipocytes or in their co-culture. In contrast to these in vitro data, in vivo epidemiological studies or clinical experiments in men are less consistent. Well controlled cross-over studies in volunteers might enlighten the differences between saturated and unsaturated fatty acids dietary intake and proatherogenic inflammation effects.

\section{Key words}

Diet $\bullet$ Fatty acids $\bullet$ Lipoproteins $\bullet$ Inflammation

\section{Corresponding author}

R. Poledne, IKEM-LVA, Vídeňská 1958/9, 14021 Prague 4, Czech Republic. Fax: +420241721574. E-mail: rudolf.poledne@ikem.cz

Saturated fatty acids (SAFA) intake was proven to increase blood cholesterol concentration more than a half century ago. The pioneer nutrition studies of Keys (Keys 1952) at the end of World War II on volunteers and later epidemiological studies (Keys et al. 1966) in seven different countries documented the quantitative relationship of fatty acid intake and total cholesterol concentration and its relation to coronary heart disease mortality. The hypercholesterolemic effect of saturated fatty acids is mediated by lipoprotein receptors on the membranes of several cells (Brown and Goldstein 1983). The immediate effect of dietary saturated fatty acids transported by portal vein to the liver directly influences hepatic lipoprotein receptors (Havel 1986) and then intravasal concentration of low density lipoprotein (LDL). Replacement of SAFA by polyunsaturated fatty acids (PUFA) increases all lipoprotein fractions but the effect on LDL-cholesterol is the most important. It was documented 30 years ago that this effect is due to decreased clearance of LDL particles measured in vivo (Shepherd et al. 1980).

Similarly to the Seven Countries Study, the epidemiological project employing the migration effect on dietary habits also documented that an increased proportion of SAFA in calorie intake showed a coronary morbidity-mortality gradient (Kato et al. 1973). A proportion below $10 \%$ of calorie intake was associated with a low risk. It is very probable that the interaction between the intake of SAFA and PUFA is more important. The Zutphen Study (Kromhout et al. 1990) did not confirm the original association of cholesterol concentration with an increase in coronary mortality and documented substantial changes in diet consumption when 1960's and 1980's were compared. On the other hand, the Lipid Research Clinic's 12-year follow-up confirmed an adverse effect of SAFA intake to cardiovascular disease but this effect was independent of plasma cholesterol level (Esrey et al. 1996). The largest prospective American Nurses Study (Hu et al. 2000) demonstrated only a weak correlation between SAFA intake and the risk of coronary heart disease similarly to weak effect when analyzing different dietary influence on cardiovascular disease risk. It is very probable that some 
other associated protective nutritional factors and/or a new metabolic effect related to increased obesity influence might play a role.

It is interesting to note that more recent studies demonstrated a rather weak proof of an adverse effect of SAFA intake on coronary disease than older epidemiological studies. The effect of continuous changes and improvement of dietary habits in industrialized countries, on the one hand, together with an increasing prevalence of obesity and predominantly increasing volume of visceral fat, on the other hand, might be important. This hypothesis is supported by a metaanalysis of 16 prospective cohort studies (predominantly from the last two decades) which found no evidence for an association of dietary SAFA intake with an increased risk of coronary heart disease (Siri-Tarino et al. 2010).

\section{Changes in relative importance of individual cardiovascular disease risks}

Over the last two decades, the relative importance of individual risk factors for coronary heart disease development has been gradually changed. We were able to document that the most manifest difference between young myocardial infarction survivors and adequate population control in the 1980s in the Czech population was the difference in LDL-cholesterol concentration. This effect is gradually decreasing and it has completely disappeared recently (Poledne et al. 2008). On the contrary, the difference in HDL-cholesterol concentration and predominantly waist circumference are differentiating myocardial infarction patients from the control population at the same time. It is generally accepted that so called "metabolic syndrome" is now the most important risk of premature myocardial infarction (Expert Panel 2001). It is questionable if abdominal obesity, insulin resistance, hypertension, hypertriglyceridemia or low HDL-cholesterol concentration originated from a single unrelated mechanism (syndrome differentiation) or whether all these pathologies arise from a distinct origin. Quite strikingly, all aspects of this "syndrome" have been closely associated with proinflammation status (Expert Panel 2001). There is considerable evidence that abundant visceral fat is a key etiologic factor in the development of this complex and very frequent disease. Ectopic adipose tissue is not only furnishing free fatty acids in the post-absorptive period but it is also producing stimulatory proinflammation status (Montague and O'Rahilly 2000). Accordingly, visceral fat is producing not only metabolic disease but also inflammatory disease. High dietary fat intake has long been proposed as a causative factor (Montague and O'Rahilly 2000) but it is not necessarily the quantity but the quality of dietary fat which predicts a metabolic effect on atherosclerosis development.

\section{A new negative effect of saturated fatty acids on increasing risk of cardiovascular disease}

It has been shown that an elevated consumption of saturated fatty acids might be directly related to proinflammation status (Suganami et al. 2005). This stimulatory effect of proinflammation appeared both in monocyte/macrophages and also in adipocytes. Palmitate activates proinflammatory activity in a tissue culture of adipocytes (Ajuwon and Spurlock 2005) as well as in human macrophages (Laine et al. 2007). Stimulation of the inflammation process is probably limited only to SAFA because the differential effect of SAFA and PUFA was recently demonstrated (Han et al. 2010). Laurate, palmitate and stearate stimulate $\kappa \mathrm{B}$ activation, whereas n3 PUFA are able to inhibit it (Lee et al. 2004). Several studies have demonstrated that this effect is mediated by the Toll-like receptor 4 (TLR4), a receptor that binds bacterial lipopolysaccharides (LPS) (Suganami et al. 2007). The mechanism by which SAFA activate the regulative receptor TLR4 may be due to TLR4 number, protein dimerization and changes in lipid raft. All these three mechanisms have been demonstrated to enhance inflammatory effects (Lee et al. 2004, 2006).

Recognition of invading pathogens and starting a host defence against them by pattern recognition receptors including TLR's had been discovered during the last decade (for review see O'Neill 2006). It has been proven that TLR's on the monocyte surface activate a downstream signaling pathway to produce immune mediators such as cytokines (for example, IL-6). As monocytes and monocyte derived macrophages start the atherogenous process, it might be speculated that this regulation is also involved in so-called "sterile inflammation" at the beginning of this pathology (for review see Lee and Hwang 2006). This hypothesis was confirmed by results of Miller et al. (2005) documenting that TLR4 stimulation of proinflammatory cytokines by minimally oxidized LDL is probably one of the most important stimulatory effects of atherogenesis (Wong et al. 2009).

A recent study (Schwartz et al. 2010) sheds new light on these contradictory findings documenting the 
participation of LPS which is a potent inducer of inflammation. LPS is normally present in low concentrations in healthy individuals because of its release by bacterial flora in the intestine due to a subclinical infection and of its presence in some food. Schwartz et al. (2010) demonstrated that SAFA are able to amplify the response to low (physiological) concentration of LPS by a parallel signaling pathway to TLR4. As plasma concentrations of LPS are elevated in obesity insulin resistance, type 2 diabetes and after highfat meals (Cani et al. 2007, 2008), this type of regulation of inflammation, which involves LPS might be important in obesity inducing diabetes and high risk of atherogenesis.

It is well known from numerous epidemiological studies that inflammatory markers (predominantly high sensitivity C reactive protein - hsCRP) are good predictors of clinical complications of atherosclerosis. Monocyte and monocyte-derived macrophages are trapped in adipose tissue (Weisberg et al. 2003) in obesity and insulin resistance (Permana et al. 2006). It is well documented that macrophages are accumulated in adipose tissue in obesity (Weisberg et al. 2003) and SAFA stimulate adipose tissue inflammation by the above described pathways. It is very probable that high dietary intake of SAFA in majority of industrialized developed societies (but recently also in some developing countries) might be a proatherogenic not only due to increased LDL-cholesterol concentration but also more directly. Monocytes and macrophages play a pivotal role in atherogenesis and their accumulation in subendothelial space of arteries in early stages of this disease. The high intake of SAFA influencing proinflammatory status might be a most important atherogenic effect produced by an "unhealthy" diet. It might be the case that not all SAFA possess this potential. It has been shown that there is a difference when comparing the proinflammatory effect of palmitate and stearate (Lee and Hwang 2006). It is possible that a decreased intake of SAFA for prevention of cardiovascular disease is potentially participating in the effect of regulation of proinflammatory status.

\section{Proinflammatory effect of saturated fatty acids studied in vivo in men}

Several dietary studies on inflammation and CRP concentration have been published during the last decade. The large National Health and Nutrition
Examination Summary (NHANES 99-00) (King et al. 2003) found an effect of dietary fibre intake to hsCRP concentration, whereas the effect of saturated, monounsaturated and polyunsaturated fatty acids did not reach a statistical significance when comparing the lowest quartile and highest quartile. This result might be caused by the overlaying effect of total fat consumption as a trend from the lowest quartile to the highest quartile of the total fat consumption (from $50 \mathrm{~g}$ /day to more than $105 \mathrm{~g} /$ day) which was the second most important variable affecting CRP concentration after dietary fibre intake. An association between dietary pattern and several plasma biomarkers of cardiovascular disease risk analyzed in a subsample from the Health Professional Studies Follow-Up Study documented a slightly significant trend of SAFA intake from the lowest to the highest quartile (Fung et al. 2001). Unfortunately, it might be partly influenced by a similar trend in the low physical activity, smoking and etc. accompanying the trend from the lowest to the highest quartile. On the contrary, the methods used by Baer et al. (2004) for analyzing dietary fatty acid effect on plasma markers of inflammation were correct. It was a randomized cross-over well controlled study with 50 volunteers consuming six different diets for 5 weeks. The most impressive effect was found in the increasing fibrinogen concentrations by dietary stearic acid. The only diet significantly increasing hsCRP concentration compared to a high-carbohydrate diet was a diet enriched with trans fatty acids (TFA). No significant effect of diet enriched with lauric, myristic, palmitic as well as stearic acid was found. Unfortunately, this non-significant effect might be strongly influenced by the consumption of oleic and linoleic acids which were almost identical in all the diets. Then the proportion of saturated (+TFA) to unsaturated fatty acids (+PUFA) was not changed.

It might be summarized that contrary to the evidence on stimulation of inflammation by SAFA in in vitro experiment, the epidemiological and clinical study results are less consistent. They are very probably influenced by various methodological problems. Food frequency and a one day dietary record are not very accurate tools but they are the only possible approaches in large studies. Better controlled cross-over studies in volunteers are needed to draw more correct data of the differences between the SAFA and PUFA effect on inflammation parameters in vivo.

\section{Conflict of Interest}

There is no conflict of interest. 


\section{Acknowledgements}

This work as supported by grant MZO 00023001 (IKEM), Ministry of Health, Czech Republic.

\begin{abstract}
Abbreviations
SAFA - saturated fatty acid, PUFA - polyunsaturated fatty acid, TFA - trans fatty acid, LDL - low density lipoprotein, HDL - high density lipoprotein, CRP C-reactive protein, LPS - lipopolysaccharides, TLR4 Toll like receptor 4, CVD - cardiovascular disease.
\end{abstract}

\section{References}

AJUWON KM, SPURLOCK ME: Palmitate activates the NF- $\mathrm{kB}$ transcription factor and induces IL-6 and TNFalpha expression in 3T3-L1 adipocytes. J Nutr 135: 1841-1846, 2005.

BAER DJ, JUDD JT, CLEVIDENCE BA, TRACY RP: Dietary fatty acids affect plasma markers of inflammation in healthy men fed controlled diets: a randomized cross-over study. Am J Clin Nutr 79: 969-973, 2004.

BROWN MS, GOLDSTEIN JL: Lipoprotein receptor in the liver: control signals for plasma cholesterol traffic. J Clin Invest 72: 743-747, 1983.

CANI PD, AMAR J, IGLESIAS MA, POGGI M, KNAUF C, BASTELICA D, NEYRINCK AM, FAVA F, TUOHY KM, CHABO C, WAGET A, DELMÉE E, COUSIN B, SULPICE T, CHAMONTIN B, FERRIÈRES J, TANTI JF, GIBSON GR, CASTEILLA L, DELZENNE NM, ALESSI MC, BURCELIN R: Metabolic endotoxemia initiates obesity and insulin resistance. Diabetes 56: 1761-1772, 2007.

CANI PD, BIBILONI R, KNAUF C, WAGET A, NEYRINCK AM, DELZENNE NM, BURCELIN R: Changes in gut microbiota control metabolic endotoxemia-induced inflammation in high-fat diet-induced obesity and diabetes in mice. Diabetes 57: 1470-1481, 2008.

ESREY KL, JOSEPH L, GROVER SA: Relationship between dietary intake and coronary heart disease mortalit: lipid research clinics prevalence follow-up study. J Clin Epidemiol 49: 211-216, 1996.

EXPERT PANEL: Executive summary of the third report of the National Cholesterol Education Program (NCEP) Expert Panel on detection, evaluation, and treatment of high blood cholesterol in adults (Adult Treatment Panel III). JAMA 285: 2486-2497, 2001.

FUNG TT, RIMM EB, SPIEGELMAN D, RIFAI N, TOFLER GH, WILLET WC, HU FB: Association between dietary pattern and plasma biomarkers of obesity and cardiovascular disease risk. Am J Clin Nutr 73: 61-67, 2001.

HAN CY, KARGI AY, OMER M, CHAN CK, WABITSCH M, O'BRIEN WIGHT TN, CHAIT A: Differential effect of saturated and unsaturated free fatty acids on the generation of monocyte adhesion and chemotactic factors by adipocytes: dissociation of adipocyte hypertrophy from inflammation. Diabetes 59: 386-396, 2010.

HAVEL RJ: Functional activities of hepatic lipoprotein receptors. Annu Rev Physiol 48: 119-134, 1986.

HU FB, RIMM EB, STAMPFER MJ, ASCHERIO A, SPIEGELMAN D, WILLETT WC: Prospective study of major dietary patterns and risk of coronary heart disease in men. Am J Clin Nutr 72: 912-921, 2000.

KATO H, TILLOTSON J, NICHAMAN MZ, RHOADS GG, HAMILTON HB: Epidemiologic studies of coronary heart disease and stroke in Japanese men living in Japan, Hawaii and California. Am J Epidemiol 97: 372-385, 1973.

KEYS A: Human atherosclerosis and the diet. Circulation 5: 115-118, 1952.

KEYS A, ARAVANIS C, BLACKBURN HW, VAN BUCHEM FS, BUZINA R, DJORDJEVIĆ BD, DONTAS AS, FIDANZA F, KARVONEN MJ, KIMURA N, LEKOS D, MONTI M, PUDDU V, TAYLOR HL: Epidemiological studies related to coronary heart disease: characteristic of men aged 40-59 in seven countries. Acta Med Scand Suppl 460: 1-392, 1966.

KING DE, EGAN BM, GEESEY ME: Relation of dietary fat and fiber to elevation of C-reactive protein. Am J Cardiol 92: 1335-1339, 2003.

KROMHOUT D, DE LEZENNE COULANDER C, OBERMANN-DE BOER GL, VAN KAMPEN-DONKER M, GODDIJN E, BLOEMBERG BP: Changes in food and nutrient intake in middle-aged men from 1960 to 1985 (the Zutphen Study) Am J Clin Nutr 51: 123-129, 1990. 
LAINE PS, SCHWARTZ EA, WANG Y, ZHANG WY, KARNIK SK, MUSI N, REAVEN PD: Palmitic acid induces IP-10 expression in human macrophages via NF-kappaB activation. Biochem Biophys Res Commun 358: 150$155,2007$.

LEE JY, ZHAO L, YOUN HS, WEATHERILL AR, TAPPING R, FENG L, LEE WH, FITZGERALD KA, HWANG DH: Saturated fatty acid activates but polyunsaturated fatty acid inhibits Toll-like receptor 2 dimerized with Toll-like receptor 6 or 1. J Biol Chem 279: 16971-16979, 2004.

LEE JY, HWANG DN: The modulation of inflammatory gene expresion by lipids: mediation through Toll-like receptors. Mol Cells 21: 174-185, 2006.

MILLER YI, VIRIYAKOSOL S, WORRALL DS, BOULLIER A, BUTLER S, WITZTUM JL: Toll-like receptor 4-dependent and -independent cytokine secretion induced by minimally oxidized low-density lipoprotein in macrophages. Arterioscler Thromb Vasc Biol 25: 1213-1219, 2005.

MONTAGUE CT, O'RAHILLY S: The perils of portliness. Causes and consequences of visceral adiposity. Diabetes 49: 883-888, 2000.

O'NEILL LA: How Toll-like receptors signal: what we know and what we don't know. Curr Opin Immunol 18: 3-9, 2006.

PERMANA PA, MENGE C, REAVEN PD: Macrophage-secreted factors induce adipocyte inflammation and insulin resistance. Biochem Biophys Res Commun 341: 507-514, 2006.

POLEDNE R, ŠKODOVÁ Z, CÍFKOVÁ R, ADÁMKOVÁ V, BRUTHANS J, LÁNSKÁ V: Trends in ischemic heart disease mortality in post-communist countries using the Czech population as an example. Atherosclerosis Suppl 9: 9, 2008.

SCHWARTZ EA, ZHANG WY, KARNIK SK, BORWEGE S, ANAND VR, LAINE PS, SU Y, REAVEN PD: Nutrient modification of the innate immune response: a novel mechanism by which saturated fatty acids greatly amplify monocyte inflammation. Arterioscler Thromb Vasc Biol 30: 802-808, 2010.

SHEPHERD J, PACKARD CJ, GRUNDY SM, YESHURUN D, GOTTO AM JR, TAUNTON OD: Effects of saturated and polyunsaturated fat diets on the chemical composition and metabolism of low density lipoproteins in man. J Lipid Res 21: 91-99, 1980.

SIRI-TARINO PW, SUN Q, HU FB, KRAUSS RM: Meta-analysis of prospective cohort studies evaluating the association of saturated fat with cardiovascular disease. Am J Clin Nutr 91: 535-546, 2010.

SUGANAMI T, NISHIDA J, OGAWA Y: A paracrine loop between adipocytes and macrophages aggravates inflammatory changes: role of free fatty acids and tumor necrosis factor alpha. Arterioscler Thromb Vasc Biol 25: 2062-2068, 2005.

WEISBERG SP, MCCANN D, DESAI M, ROSENBAUM M, LEIBEL RL, FERRANTE AW JR: Obesity is associated with macrophage accumulation in adipose tissue. J Clin Invest 112: 1796-1808, 2003.

WONG SW, KWON MJ, CHOI AM, KIM HP, NAKAHIRA K, HWANG DH: Fatty acids modulate Toll-like receptor 4 activation through regulation of receptor dimerization and recruitment into lipid rafts in a reactive oxygen species-dependent manner. J Biol Chem 284: 27384-27392, 2009. 